\title{
Impella protected percutaneous coronary intervention on the last remaining highly calcified coronary artery facilitated by shockwave intravascular lithotripsy and levosimendan infusion
}

\author{
Piotr Rola',2, Adrian Włodarczak', Artur Jastrzębski', Mateusz Barycki², Karol Turkiewicz', Jan Jakub Kulczycki', \\ Marek Szudrowicz' ${ }^{1}$ Maciej Pęcherzewski', Adrian Doroszko³, Maciej Lesiak
}

'Department of Cardiology, The Copper Health Center, Lubin, Poland

2Department of Cardiology, Provincial Specialized Hospital in Legnica, Poland

3Department of Internal Medicine, Hypertension and Clinical Oncology, Wroclaw Medical University, Wrocław, Poland

${ }_{4}^{4} 1^{\text {st }}$ Department of Cardiology, Poznan University of Medical Sciences, Poznań, Poland

\author{
Correspondence to: \\ Piotr Rola, MD, PhD, \\ Department of Cardiology, \\ Provincial Specialized \\ Hospital in Legnica, \\ Iwaszkiewicza 5, \\ 59-220 Legnica, Poland, \\ phone: +48 888272007 , \\ e-mail: \\ piotr.rola@gmail.com \\ Copyright by the Author(s), \\ 2021 \\ Kardiol Pol. 2021; \\ 79 (10): 1145-1146; \\ DOI: 10.33963/KP.a2021.0062 \\ Received: \\ June 14, 2021 \\ Revision accepted: \\ July 13, 2021 \\ Published online: \\ July 14, 2021
}

A 67-year-old male, with hyperlipidemia, hypertension, type 2 diabetes mellitus, and persistent atrial fibrillation was admitted to the Department of Cardiology with a non-ST segment elevation myocardial infarction. Physical examination revealed tachycardia, dyspnea with rales and crackles on auscultation (Killip-Kimball II). Transthoracic echocardiography showed the enlarged hypokinetic left ventricular with coexisting akinesia of the inferior wall (left ventricular end-diastolic/left ventricular end-systolic diameters of $59 \mathrm{~mm} / 53 \mathrm{~mm})$, reduced left ventricular ejection fraction (25\%), severe functional mitral regurgitation, and a moderate amount of fluid in both pleural cavities.

After initial pharmacological stabilization, coronary angiogram was performed and revealed a chronic total occlusion of the right coronary artery (Figure 1A) and circumflex, with coexisting significant highly calcified stenosis of the left main artery (LM) and multilevel highgrade stenosis of the left anterior descending artery (LAD) (Figure 1B). The patient was referred to the local Heart Team and due to high risk (SYNTAX Score = 49.5 points; EuroSCORE $\|=9 \%$ ) and subtotal occlusion of the distal part of the LAD, he was unsuitable for surgery and a rescue percutaneous coronary intervention (PCI) was proposed.

In order to optimize the treatment of heart failure before $\mathrm{PCl}$, we performed a puncture of both pleural cavities and beyond standard pharmacotherapy (beta-blocker, intravenous loop diuretic, angiotensin-converting-enzyme inhibitors, mineralocorticoid receptor antagonist) we administrated 24-hour intravenous infusion of levosimendan $(0.1 \mu \mathrm{g} / \mathrm{kg} / \mathrm{min}$ - cumulative dose $12.5 \mathrm{mg}$ ). Two days later, we performed $\mathrm{PCl}$ by the right radial approach using the EBU 3.5 Guide Catheter (7F) (Medtronic Ireland, Galway, Ireland) with additional Impella CP (Abiomed, Denver, CO, USA) support (flow $3.3 \mathrm{l} / \mathrm{min}$ ), implemented by the right femoral access. After wiring the LAD with Fielder XT (Asahi-INTECC Co., Aichi, Japan) enhanced by Caravel microcatheter (Asahi-INTECC) and subsequent exchange of a guidewire on Sion blue ES (Asahi-INTECC), we performed multiple high pressure (up to $22 \mathrm{~atm}$ ) inflation of the semi-compliant $1.5 \times 20 \mathrm{~mm}$ and non-compliant (NC) $2.5 \times 20 \mathrm{~mm}$ and $3.0 \times 20 \mathrm{~mm}$ balloon catheter. Three overlapping drug-eluting stents (DES) Resolute Onyx (Medtronic) were implanted from the middle to distal the part of the LAD $-2.5 \times 30 \mathrm{~mm}$ (18 atm); $2.25 \times 38 \mathrm{~mm}$ (16 atm); $2.0 \times 26 \mathrm{~mm}$ (14 atm). In the next step, we performed pre-dilation of the LM and proximal part of the LAD. However, despite using high-pressure inflation (24 atm), we observed a significant "dogbone effect" on the $3.0 \mathrm{~mm}$ NC-catheter (Figure 1C).

Hence, we performed the shockwave intravascular lithotripsy (S-IVL) using a $3.0 \times 12 \mathrm{~mm}$ catheter (Shockwave Medical Inc, Santa Clara, (A, USA), and after 80 ultrasonic pulses, we achieved full expansion (Figure 1D). From the proximal part of the LM, we implanted two additional overlapping DES $(3.5 \times 18 \mathrm{~mm}$ and 


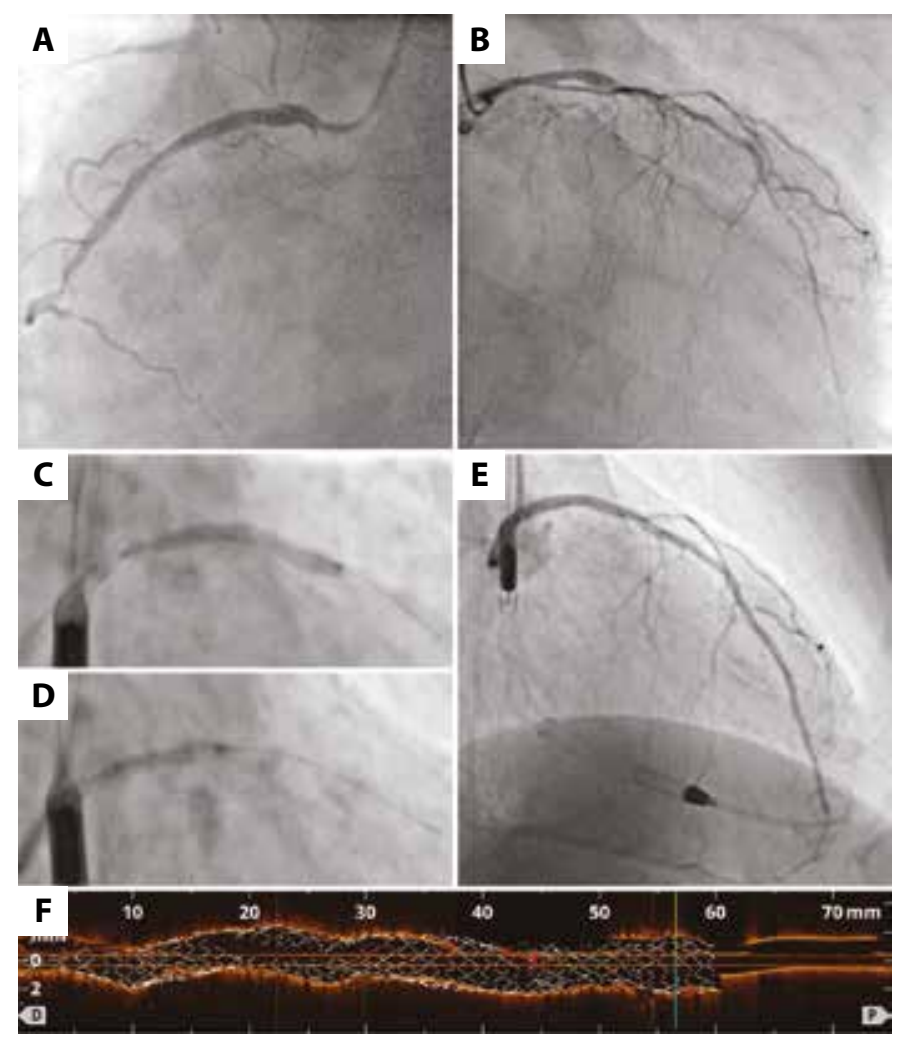

Figure 1. A. Coronary angiography of the right coronary artery. B. Coronary angiography of the left main and the left anterior descending. C. Significant under-expansion on the $3.0 \mathrm{~mm}$ non-complaint balloon catheter. D. Full expansion of Shockwave Intravascular Lithotripsy $3.0 \times 12 \mathrm{~mm}$ balloon catheter. E. Final angiographic result of the procedure. F. Final result confirmed in optical coherence tomography.
$3.0 \times 38 \mathrm{~mm}$ ). Finally, a proximal optimization technique was performed with NC $4.0 \times 15 \mathrm{~mm}$ (20 atm). The reasonable angiographic result (Figure 1E) was confirmed by the optical coherence tomography imaging (Figure 1F). The support pump was removed immediately after the procedure-vascular access point was closed with 2 co-acting AngioSeal 8F (Terumo Corporation, Tokyo, Japan) vascular closure devices. The patient was discharged after 13 days of hospitalization with a mild improvement of the LV function (ejection fraction of 35\%) and with reduced (moderate) mitral regurgitation.

$\mathrm{PCl}$ to the last remaining patent vessel is a high-risk procedure, as evidenced by the fact that about a quarter of patients die at 1-year follow-up [1]. In the therapy of a patient with such a poor clinical prognosis, any available armamentarium that may improve the prognosis should be involved in the therapeutic process. In this challenging case, we used a wide range of factors potentially affecting the outcome - an intravenous infusion of levosimendan [2], mechanical circulatory support with Impella [3], and plaque modification with S-IVL $[4,5]$ in order to obtain a favorable clinical outcome. Initial intensive heart-failure pharmacotherapy allowed to restrict hemodynamic support to the periprocedural period. If adequate optimization could not be achieved earlier, maintaining Impella CP assistance might be a valuable support to conventional HF therapy; yet bleeding or access-related complications may affect potential benefits.

\section{Article information}

Conflict of interest: None declared.

Open access: This article is available in open access under Creative Common Attribution-Non-Commercial-No Derivatives 4.0 International (CC BY-NC-ND 4.0) license, allowing to download articles and share them with others as long as they credit the authors and the publisher, but without permission to change them in any way or use them commercially. For commercial use, please contact the journal office at kardiologiapolska@ptkardio.pl.

How to cite: Rola P, Włodarczak A, Jastrzębski A, et al. Impella protected percutaneous coronary intervention of last remain highly calcified coronary artery facilitated by Shockwave Intravascular Lithotripsy and levosimendan infusion. Kardiol Pol. 2021; 79(10): 1145-1146, doi: 10.33963/KP.a2021.0062.

\section{REFERENCES}

1. Shoaib A, Rashid M, Kontopantelis E, et al. British Cardiovascular Intervention Society (BCIS) and the National Institute for Cardiovascular Outcomes Research (NICOR). Clinical characteristics and outcomes from percutaneous coronary intervention of last remaining coronary artery: an analysis from the British Cardiovascular Intervention Society database. Circ Cardiovasc Interv. 2020; 13(9): e009049, doi: 10.1161/CIRCINTERVENTIONS.120.009049, indexed in Pubmed: 32873051.

2. Husebye T, Eritsland J, Müller C, et al. Levosimendan in acute heart failure following primary percutaneous coronary intervention-treated acute ST-elevation myocardial infarction. Results from the LEAF trial: a randomized, placebo-controlled study. Eur J Heart Fail. 2013; 15(5): 565-572, doi: 10.1093/eurjhf/hfs215, indexed in Pubmed: 23288914.

3. Russo G, Burzotta F, Aurigemma C, et al. Can we have a rationalized selection of intra-aortic balloon pump, Impella, and extracorporeal membrane oxygenation in the catheterization laboratory? Cardiol J.2020 [Epub ahead of print], doi: 10.5603/CJ.a2020.0182, indexed in Pubmed: 33346366.

4. WłodarczakA, Kulczycki J, Furtan Ł, et al. Rotational atherectomy and intravascular lithotripsy: two methods versus a single lesion. Kardiol Pol. 2021; 79(6): 712-713, doi: 10.33963/KP.15962, indexed in Pubmed: 33890748.

5. Dini CS, Tomberli B, Mattesini A, et al. Intravascular lithotripsy for calcific coronary and peripheral artery stenoses. Eurolntervention. 2019; 15(8): 714-721, doi: 10.4244/EIJ-D-18-01056, indexed in Pubmed: 31062700. 